\title{
George Sand, Five Comedies
}

\section{Seth Whidden}

\section{(2) OpenEdition}

\section{Journals}

\section{Édition électronique}

URL : http://journals.openedition.org/studifrancesi/36452

DOI : 10.4000/studifrancesi.36452

ISSN : 2427-5856

\section{Éditeur}

Rosenberg \& Sellier

\section{Édition imprimée}

Date de publication : 1 juillet 2005

Pagination : 186-187

ISSN : 0039-2944

\section{Référence électronique}

Seth Whidden, «George Sand, Five Comedies », Studi Francesi [En ligne], 145 (XLIX | I) | 2005, mis en

ligne le 30 novembre 2015, consulté le 22 avril 2021. URL : http://journals.openedition.org/ studifrancesi/36452 ; DOI : https://doi.org/10.4000/studifrancesi.36452

\section{Ce document a été généré automatiquement le 22 avril 2021.}

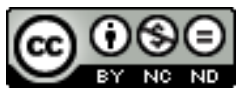

Studi Francesi è distribuita con Licenza Creative Commons Attribuzione - Non commerciale - Non opere derivate 4.0 Internazionale. 


\title{
George Sand, Five Comedies
}

\author{
Seth Whidden
}

\section{RÉFÉRENCE}

GEORGE SAND, Five Comedies, traduction de E. H. et A. M. BLACKMORE et Francine GIGUERE, Albany, NY (États-Unis), State University of New York Press, 2003, pp. 272.

1 Comme le suggère le titre, cette anthologie regroupe, en anglais pour la toute première fois, les deux comédies dramatiques les mieux connues de Sand (Le Marquis de Villemer et Françoise) ainsi que les trois pièces en un acte les plus importantes de son œuvre (Le Pavé, Le Lis du Japon et Un Bienfait n'est jamais perdu). Mais, avant les textes, se trouve une présentation de l'œuvre et de la vie de Sand et un survol général du théâtre du XIX ${ }^{\mathrm{e}}$ siècle. Les traducteurs soulignent le fait que Sand fut dramaturge pendant presque toute sa vie et expliquent les quatre "générations» de la réception de l'œuvre dramatique sandienne (de la première, Sainte-Beuve se range parmi ceux qui ont apprécié les pièces; la deuxième critique Sand pour son manque de réalisme; la troisième, celle $\mathrm{du} \mathrm{XX}^{\mathrm{e}}$ siècle, a oublié presque entièrement l'œuvre de Sand; et actuellement on voit un intérêt envers son œuvre en plein essor, aussi bien œuvres en prose qu'œuvres dramatiques). Dans cette introduction, les comparaisons avec d'autres dramaturges et les références intertextuelles visent en grande partie la tradition théâtrale britannique, ce qui risque d'aliéner des lecteurs anglophones venant à ce texte par intérêt pour Sand et sans autres connaissances théâtrales anglo-saxonnes. Pour respecter le contexte historico-littéraire de ces pièces, peut-être aurait-il fallu admettre que le XIX ${ }^{e}$ siècle n'est pas aussi riche en pièces qu'en poèmes ou romans. On peut comprendre l'intérêt que les traducteurs portent à leur travail, mais quelques proclamations tendent à l'exagération; tel est le cas quand on lit que le personnage du Marquis de Villemer est «sans doute l'un des héros les plus complexes et ambigus» du théâtre du milieu du XIX ${ }^{e}$ (p. 9, nous traduisons). La constatation, peut-être fondée, n'aboutit pas à une réclamation si prestigieuse, vu le petit nombre de réussites du théâtre français de ce temps. 
2 Mais, à part ces remarques de détail, les traductions elles-mêmes sont d'une haute qualité et extrêmement lisibles; les lecteurs anglophones les trouveront fluides et fidèles aux textes de Sand. Les notes fournies par les traducteurs (dans l'introduction et pour chaque pièce) seront surtout utiles pour un public anglophone ne connaissant pas des points de repères «de base» de la vie française au XIX ${ }^{e}$ siècle: ainsi en voit-on une expliquant que le faubourg Saint-Germain est «un quartier particulièrement aristocratique de Paris» au début du Marquis de Villemer (p. 265 n. 1, nous traduisons). Avec l'apparat critique qui accompagne ces pièces (l'introduction, les notes déjà mentionnées, une chronologie sandienne et une bibliographie utile), ces cinq pièces trouveront une place chez tout amateur de Sand et du théâtre français de cette époque. 